This is the author's post-print of the article accepted for publication which appears in a revised form, subsequent to editorial input by Cambridge University Press.

Citation: Bishop FL, Amos N, Yu H, Lewith GT. (2012) Health care sector and complementary medicine: Practitioners' experiences of delivering acupuncture in the public and private sectors. Primary Health Care Research \& Development, 13, 269-278. doi: 10.1017/S1463423612000035. Epub 2012 Feb 9.

Available:

http://journals.cambridge.org/action/displayAbstract?fromPage $=$ online\&aid=8633794

Copyright holder: Cambridge University Press

\title{
Health care sector and complementary medicine: Practitioners' experiences of delivering acupuncture in the public and private sectors
}

Running title: Acupuncture in the public and private sectors 
Authors: Felicity L Bishop*, Nicola Amos, He Yu, George T Lewith

* Corresponding author: Dr Felicity L Bishop, Primary Medical Care, Aldermoor Health Centre, Aldermoor Close, Southampton, Hampshire, SO16 5ST. UK. Email:

F.L.Bishop@southampton.ac.uk. Fax: 0238070 1125. Phone: 02380241072.

Felicity L Bishop. CPsychol PhD. Arthritis Research UK Career Development Fellow, University of Southampton School of Medicine. F.L.Bishop@ southampton.ac.uk

Nicola Amos. BM. At the time of this research Nicola was a medical student at the University of Southampton School of Medicine. Nicola is now a Foundation Year One Doctor at Salisbury District Hospital.nicola.amos@salisbury.nhs.uk.

He Yu. Evidence-based Chinese Medicine PhD. University lecturer, Beijing University of Chinese medicine. Yuhe221@126.com.

George T Lewith. MA MD FRCP. Professor of Health Research, University of Southampton School of Medicine. g13@ soton.ac.uk. 


\begin{abstract}
$\underline{\text { Abstract }}$
$\underline{\operatorname{Aim}}$

The aim was to identify similarities and differences between private practice and NHS in practitioners' experiences of delivering acupuncture to treat pain. We wished to identify differences which could affect patients' experiences and inform our understanding of how trials conducted in private clinics relate to NHS clinical practice
\end{abstract}

\title{
Background
}

Acupuncture is commonly used in primary care for low back pain and is recommended in the NICE guidelines. Previous studies have identified differences in patients' accounts of receiving acupuncture in the NHS and in the private sector. The major recent UK trial of acupuncture for back pain was conducted in the private sector.

\section{$\underline{\text { Methods }}$}

Semi-structured qualitative interviews were conducted with 16 acupuncturists who had experience of working in the private sector $(n=7)$, in the NHS $(n=3)$ and in both sectors $(n=6)$. The interviews lasted between 24 and 77 minutes (median $=49$ minutes) and explored acupuncturists' experiences of treating patients in pain. Inductive thematic analysis was used to identify similarities and differences across private practice and the NHS. 


\section{Findings}

The perceived effectiveness of acupuncture was described consistently and participants felt they did (or would) deliver acupuncture similarly in NHS and private practice. In both sectors patients sought acupuncture as a last resort and acupuncturist-patient relationships were deemed important. Acupuncture's availability differed across sectors: in the NHS it was constrained by Trust policies and in the private sector by patients' financial resources. There were greater opportunities for autonomous practice in the private sector and regulation was important for different reasons in each sector. In general, NHS practitioners had Western focussed training and also used conventional medical techniques while private practitioners were more likely to have Traditional Chinese training and to practise other complementary therapies in addition to acupuncture. Future studies should examine the impact of these differences on patient's clinical outcomes.

Keywords: Health personnel; Public sector; Private sector; Acupuncture; Qualitative Research. 
In the UK, complementary and alternative medicine (CAM) therapies are predominantly delivered and accessed in the private sector, but they have long had a foothold in the public sector. Homeopathic hospitals have always been part of the National Health Service (NHS) and $40 \%$ of GPs referred to CAM therapies at the turn of the century (Thomas et al. 2001). The UK coalition government appears to want to encourage more access to CAM in the NHS (Secretary of State for Health 2010) thus increasing the availability of CAM for those patients who cannot afford to access it in the private sector. However, truly equal access depends on the equivalence of the services being delivered in the public and private sectors. To explore the equivalence of CAM delivery across sectors, we wished to compare practitioners' experiences of working in the NHS and private practice and we chose to focus our research on acupuncture.

According to a major European survey, 7.8 million people in the UK suffer from chronic pain, $35 \%$ of whom experience pain all the time and $12 \%$ of whom use acupuncture (Breivik et al. 2006). Acupuncture is currently available in the NHS via physiotherapy departments, hospital pain clinics, and primary care (Dale 1997; Thomas et al. 2003). There is evidence that acupuncture is safe (White et al. 2001), cost-effective (Wonderling et al. 2004; Willich et al. 2006; Ratcliffe et al. 2006), and effective for a range of painful conditions, including chronic low back pain (Furlan et al. 2005; Manheimer et al. 2005), neck pain (Trinh et al. 2006), shoulder pain (Green et al. 2005), migraine (Linde et al. 2009a), and headache (Linde et al. 2009b). This evidence-base has been formally recognised for some conditions, for example acupuncture was officially recommended in the UK's National Institute for Health and Clinical Excellence's (NICE) clinical guidelines for managing non-specific persistent low back pain in primary care (Savigny et al. 2009). However, the major UK-based RCT of acupuncture for back pain was conducted in a private sector environment (Thomas et al. 2006) and this raises questions about the translation of evidence from one sector to another: To what extent is the acupuncture being delivered in the NHS the same as the acupuncture that has been evaluated and researched in the private sector? 
To date there have been few studies comparing NHS and private practice acupuncture in particular or CAM therapies more generally. Acupuncture can be seen as a complex intervention in which practitioners emphasise the therapeutic relationship and see themselves as providing individualised care (MacPherson et al. 2006a) and lifestyle/selfhelp advice (MacPherson, Thorpe, \& Thomas 2006a;MacPherson and Thomas 2008). Acupuncturists deliver care in the context of their individual theoretical perspectives (e.g. Western or traditional Chinese medicine) (Hughes et al. 2007) and the wider power relations that exist between acupuncture and orthodox biomedicine (Saks 1992;Dew 2000). The actual ways in which acupuncturists currently deliver acupuncture care to patients in the NHS in comparison to the private sector has not been explored in-depth, although evidence from studies of patients' experiences suggests there may be differences. CAM use in private practice is mainly self-directed directly by patients (MacPherson et al. 2006b) whereas GPs may play a role in referring patients to NHSbased CAM services. While NHS patients are generally positive about accessing CAM in what is perceived as a safe environment (Shaw et al. 2006;Evans et al. 2007), differences in patients' experiences of acupuncture between the NHS and private practice have been identified, for example in relation to holistic care (Paterson and Britten 2008).

In summary, acupuncture is a safe and relatively cost-effective treatment for pain and can be conceptualised as a complex intervention. This project aimed to identify similarities and differences between private practice and NHS in practitioners' experiences of delivering acupuncture to treat pain, with a view to informing our understanding of the relationship between the research evidence and clinical practice. This will also allow us to identify any differences that exist between these two clinical environments which could affect patients' experiences of acupuncture and their clinical outcomes. A qualitative approach was chosen to enable an in-depth and open exploration of the topic.

\section{Methodology}

\section{Design}


This study was based on face-to-face semi-structured interviews and inductive thematic analysis (Braun and Clarke 2006). Ethics approval was received from Southampton and South West Hampshire Research Ethics Committee (B) (reference number 07/HO504/196).

\section{Procedure}

The search functions on the websites of two acupuncture associations (the British Acupuncture Council and the Acupuncture Association of Chartered Physiotherapists) were used to identify acupuncturists in Hampshire. A letter and information pack were sent to a random selection of these acupuncturists and those who expressed interest in participating were contacted by the researcher to establish whether they fitted the inclusion criteria (practised acupuncture within the last 2 years, over 18, fluent in English). Acupuncturists were also asked what sector they worked in and how long they had been practicing acupuncture. Respondents were then purposively sampled in an attempt to interview a similar number of acupuncturists from the public and private sectors with some recently-qualified and some more experienced acupuncturists. Recruitment stopped when no new themes were raised in interviews with acupuncturists in private practice and no more acupuncturists practicing only in the NHS could be recruited from the local area.

Each participant took part in a single semi-structured face-to-face interview with a student researcher (NA) between January and March 2009. The topic guide consisted of a series of open-ended questions. Set opening and closing questions were supplemented by questions probing specific aspects of practice to be used only if the topic was not initiated by the interviewee (Table 1). The approach to interviewing was a neutral, realist perspective where all information was taken as new and at face value. Interviews lasted between 24 and 77 minutes (median $=49$ minutes) were audio-recorded and transcribed verbatim with identifiable details removed and names replaced by pseudonyms. Transcripts (and quotations below) were annotated with (N), (P) or (B) representing, respectively, working in the NHS, Private sector, or Both sectors. 


\section{$\underline{\text { Participants }}$}

Sixteen acupuncturists (14 women, 2 men) were interviewed: seven worked only in the private sector, three worked only in the NHS and six had experience in both sectors. Table 2 summarises the participants' characteristics.

\section{Data Analysis}

An inductive thematic analysis was undertaken following the steps suggested by Braun and Clarke (2006). Analysis began as soon as the first three interviews had been completed. In Phase 1 (familiarisation), all transcripts were read numerous times and recordings listened to extensively. In Phase 2 (coding), the lead analyst worked through the first three transcripts and generated low-level open codes (labels) that described each phrase. Similar codes were then grouped into categories and subcategories, which were applied to the remaining transcripts. In Phase 3 (searching for themes), categories and subcategories were reviewed and potential themes were identified. Table 3 shows the relationship between codes, sub-categories, categories, and themes. In Phase 4 (reviewing themes), candidate themes were checked against the categories, subcategories, and transcripts, and modified where necessary to ensure a good fit (instances of 'bad fit' were deliberately sought out to inform this process). In Phase 5 (theme definition), themes were named concisely, defined clearly in relation to each other, and related back to the research question: talk about the NHS and private sector was compared for each theme. In Phase 6 (write-up), a storyline was developed that summarised the themes in relation to the research question and eloquent and/or typical quotes were selected to illustrate key points.

\section{Findings}


Eight themes were identified and are summarised in Figure 1. The interviewees talked in broadly similar ways across the NHS and private practice in relation to four themes; differences were identified in relation to four themes.

\section{Similarities Between NHS and Private Practice}

The Perceived Effectiveness of Acupuncture was reported consistently across public and private sector practice. All practitioners typically reported that over half of patients obtained effective pain relief from acupuncture: " $60 \%$ of my patients get $50 \%$ or more relief from acupuncture in the pain clinic" (Annie, B). Acupuncture was seen to have additional effects beyond pain relief (e.g. better sleep, relaxation, tiredness) in both sectors. Dramatic examples of the effects of acupuncture were related by practitioners across both sectors, but these were described as rare: "this lady had taken 6 months off work, was bent double and I just gave her one treatment and she walked out" (Julie, P). Despite often getting good results, practitioners acknowledged that acupuncture is not effective for all patients and found it very difficult to predict in advance who would or would not respond well to treatment and how long the effects of treatment would last. Factors commonly thought to predict positive responses include younger age, acute (rather than chronic) pain, and an immediate response to needle insertion. Patient expectation was not thought to predict response: "some of the best results have been in the really skeptical" (Steph, N).

Practitioners felt that they did (or would) deliver acupuncture in broadly the same way in the NHS or in private practice: there was a Perception that acupuncture is fundamentally unchanged by healthcare sector. They also typically favoured the provision of acupuncture in both sectors. Multi-sector practitioners reported treating patients in exactly the same way in each setting, although they qualified their statements by reference to time constraints within their NHS practice. 
"I would practise the same way, with the same system and techniques. I do practise a small amount privately and I think the only difference is that in private practise I would have more time to spend with patients". (Harriet, B)

Single sector practitioners believe they would treat in exactly the same way if they were to practise in another sector, for example Gemma (P) said "It will be exactly the same treatment [in the NHS] but in half the time, you'll have 20 minutes instead of 40 minutes". Some single-sector practitioners also attended to time as a limiting factor: Private practitioners expressed concern over time constraints in the NHS and NHS practitioners believed that they would have more time with each patient in private. Three broad similarities were identified in the ways in which acupuncturists perceived and delivered acupuncture across sectors.

1. Practitioners universally treated in accordance with their training, and this involved taking detailed histories, performing physical examinations, considering lifestyle and wider factors, and developing individualised treatment plans. (The manner in which these activities were accomplished did vary between sectors and is discussed later.)

2. Practitioners universally believed that acupuncture is a safe intervention with minimal side effects and a good alternative to long term medication; a view that is sustained by the current evidence base.

3. Needling time was typically 20 minutes and while there were variations (from "in and out" to "up to 30 minutes") these did not relate to sector.

Practitioners in both sectors report that many patients access acupuncture as a last resort, frequently in desperation as no other treatment has been effective: "if it's long standing stuff people are just so sick of everything and they're so sick of taking pills specifically and the fact that no-one else seems to be able to do anything for them that they'll give anything a go" (Hannah, P). Acupuncture can also be a last resort for some practitioners. While some physiotherapists used acupuncture as a first line treatment, others preferred to use their manipulation skills first or to use acupuncture in a supportive role to control pain sufficiently to enable them to perform other therapies. 
Acupuncturist-patient relationships were important to practitioners across both sectors. Practitioners referred to the therapeutic importance of listening to and getting to know the patient, especially given that many come to acupuncture as a last resort and have had negative experiences of other health care professionals. Diagnosis was one means to listen to and get to know patients, as it frequently incorporated comprehensive investigation of contributing factors, such as lifestyle and emotional health. Practitioners hoped that, by establishing rapport, patients would be confident and trust in them and would tolerate the time it can take for acupuncture to work: "without rapport, the patient isn't likely to continue a long enough course of treatment" (Barbara, P). Some practitioners in the private sector implied that spending time with patients was important for building rapport: "we have plenty of time, GP maybe 5 minutes, we talking customer 15 minutes, we treat customer first treatment maybe 45 minutes, one hour" (Mei, P). However, several NHS practitioners did find time to develop rapport and explore patients' experiences more holistically: "I spend a lot of time talking about their lifestyle, their mood, their thoughts, their feelings" (Annie, B). Time constraints were associated with subtle differences in the therapeutic relationship across sectors; these are discussed below ("opportunities for autonomous practice").

\section{Differences Between NHS and Private Practice}

Participants talked about how the availability of acupuncture differs considerably between sectors. In the NHS, policies were imposed by Trusts in the form of guidelines, which limited the type of conditions to be treated with acupuncture (almost exclusively pain), duration of each treatment (typically 20 minutes per session), frequency of sessions (typically once per week) and overall course duration (typically 6 sessions, although one Trust was described as not limiting duration in this way). More drastically, the availability of acupuncture on any basis was also limited, in that some NHS Trusts had withdrawn all funding for acupuncture: "Very sadly it was withdrawn, it was a financial decision, several years ago. I can only do it privately because I work in a trust that won't finance it." (Florence, B). In the private sector, the access to acupuncture was limited by 
the patient's ability or willingness to pay and this was thought to make some patients expect quick positive results: "[some patients are] not very patient about how many treatments they are prepared to pay for." (Barbara, P). Some practitioners thought that paying for treatments had positive effects, encouraging patients to value their care and to co-operate with lifestyle advice. However, negative consequences were also acknowledged and some cross-sector practitioners valued the limits imposed by the NHS as they provided certainty for both patients and practitioners: “[in the NHS] I don't have to worry about whether they can afford it or not [...] [In the private sector] you don't have the luxury of the patient having a six week course." (Annie, B). Interestingly, some cross-sector practitioners talked about working with the different constraints imposed on availability in each sector to try to maximise benefit for their patients. Florence talked about how providing some acupuncture on the NHS at least allowed patients to try it before committing to paying for it in the private sector. Christine talked about working in a different way to maximise the number of patients she could treat within each session available to her in the NHS.

"[My NHS practice is like] a hamster wheel, where you get them in, you get them set up, the next one arrives, you get them in you get them set up. You let the other one free, they clear the room, you bring the next one in." (Christine, B)

Differences in availability were closely linked to differences in opportunities for autonomous practice, which could translate into differences in the co-treatments delivered as well as more subtle differences in the therapeutic relationship and the perceived effectiveness of acupuncture. These differences were seen as a consequence of the constraints imposed by the NHS that were not present in private practice.

Practitioners in both sectors had some autonomy to incorporate other therapies alongside acupuncture: "I call it [acupuncture] a tool in my toolbox". (Harriet, B). However, choice of additional therapies varied across sectors and was related to time available and whether therapies were sanctioned (or not) within the NHS. In private practice, practitioners typically used herbs, aromatherapy, reflexology, nutritional advice and homeopathy. In the NHS, practitioners tended to apply more mainstream approaches and 
concentrate on physiotherapy and hydrotherapy. More subtly, NHS constraints on treatment duration and frequency meant that acupuncturists in the NHS were less able to make collaborative and individualised decisions with patients about a course of treatment. Restricting treatment to painful conditions made it difficult to practise holistically and to treat co-morbid conditions as well as pain. Some practitioners felt that NHS constraints limited the effectiveness of acupuncture as short session times were thought to inhibit the ability to develop patient rapport. This problem could be lessened if patients had more than one painful condition, which provided a rationale for acupuncturists in the NHS to deliver twice as many treatments: "and often, funnily enough, that's what makes the difference because they have that prolonged amount of treatment." (Pauline, N).

Concerns over qualifications, training, and lack of industry regulation were expressed in both sectors, but for different reasons. Private practitioners had concerns that the relatively short duration of training often undertaken by biomedical clinicians practising Western acupuncture was insufficient for a profound understanding of the technique, whereas NHS practitioners were concerned over the high degree of variability in private sector clinics located in high street shops, and their tendency to charge for several sessions upfront. One practitioner argued that some such outlets gave the whole acupuncture industry a bad name: "the whole acupuncture profession is tainted" (Harriet, B). Practitioners in both sectors referred to the need for industry-wide standards, regulation and recognised qualifications and codes of conduct.

\section{Practitioners' explanatory theories of acupuncture, health, and illness influence their}

practice. As would be expected, there were systematic differences between the practices of acupuncturists trained in the Chinese tradition and those trained in Western acupuncture (Table 4). Practitioners' explanatory theories stemmed from their training, which, in turn, derived frequently from career orientation. NHS practitioners could access certain acupuncture courses by virtue of their existing biomedical qualifications. They often choose to train in acupuncture to expand their skills, to have a "strong armoury in the kitbag" (Steph, N). Practitioners working in the NHS tend to have very Western focussed training to which some practitioners add a small degree of Chinese influence. 
The NHS practitioners who were also physiotherapists used acupuncture as an adjunct to physiotherapy. Fewer private practitioners in our sample had biomedical qualifications and instead tended to have a Traditional Chinese training, either TCM or Five Element acupuncture or a combination. Most saw acupuncture as central to their practice, having chosen to become acupuncturists because of a perceived fit with their desired way of life: "I wanted to work with the whole person. Five Element acupuncture is a way of looking at people as though they were a microcosm of the planet." (Gemma, P). Private sector practitioners (and some NHS practitioners who were not physiotherapists) offered acupuncture as a primary treatment and saw other therapies as adjunctive.

\section{$\underline{\text { Discussion }}$}

We have identified both similarities and differences between NHS and private practice delivery of acupuncture. The most striking similarity was the consistency of perceived effectiveness across sectors, although there was also consensus around the safety of acupuncture and consensus around the perception that, if practising in another sector, an individual practitioner's techniques would be the same. Statutory industry-wide regulation of acupuncturists would be welcomed by acupuncturists in both sectors for slightly different reasons. Our study also provides evidence from practitioners' perspectives that there are differences in the acupuncture that patients receive in the NHS and private sector, which confirms and helps to explain findings from studies based on patients' experiences (Paterson \& Britten 2008). The major differences, in availability and opportunities for autonomous practice in the NHS and private practice, were seen to stem from the time-related and management constraints imposed on acupuncturists by many NHS Trusts. Some of these differences, for example in the number and frequency of sessions, in the type of co-treatments, and in the consultation style, might also translate into important differences in patients' clinical outcomes. These hypotheses receive some support from existing literature (Ezzo et al. 2000;Di Blasi et al. 2001;Price et al. 2006; Yuan et al. 2009) but need more rigorous testing in future acupuncture studies. Practitioners also felt that acupuncture practice is strongly determined by training in Western or Chinese approaches and their different explanatory models (similar to UK 
acupuncturists treating Rheumatoid Arthritis, Hughes, Goldbart, Fairhurst, \& Knowles 2007), and this was confounded with sector in that private practice was dominated by practitioners trained in a Chinese tradition (mainly TCM or Five Element, Bennetts 2007) while NHS practitioners were more likely to focus on Western techniques. We have recently conducted a survey confirming that UK acupuncturists trained in Western medical acupuncture are very likely to be working in the NHS while those trained in Chinese approaches are very likely to be working in the private sector (Bishop et al. 2011). Historically this makes sense as Western medical acupuncture was developed by clinicians already trained in conventional biomedicine for use as part of their existing clinical practices (White and the editorial board of Acupuncture in Medicine 2009). Evidence from Germany suggests that an acupuncturist's training and speciality may not affect hard patient outcomes (Witt et al. 2010), but further work is needed to explore possible effects on the processes and context of care and softer outcomes such as empowerment and satisfaction.

The credibility of our findings is strengthened by the way in which we followed explicit guidelines for thematic analysis and have described our approach transparently in this article. While we did not recruit a representative sample of acupuncturists, this is consistent with our qualitative approach. Indeed, our sample consisted of those participants who were well-placed to inform our research question and included a range of practitioners from different NHS settings (physiotherapy departments, pain clinics, primary care) and different private practice settings (complementary therapy clinics, health and beauty spas, home-based practice). By working iteratively (commencing analysis whilst interviews were still being conducted) it was possible to highlight areas of interest within early interviews and investigate them more thoroughly in subsequent interviews, which led to the identification of more detailed categories. We would have liked to interview more practitioners working only in the NHS, but unfortunately we were unable to identify many such practitioners within the short timeframe of this project. It is therefore possible that had we been able to expand our sample we would have identified additional themes. All of the research team were involved in checking emerging interpretations, which helped to ensure that idiosyncratic interpretations were challenged 
and modified and that the final report was consistent with the original data. The interviewer's identity as a medical student was known to all interviewees, and may have resulted in them using more technical language and/or taking an educative stance which would have been less likely with a different interviewee. However, we feel this dynamic is unlikely to have altered the fundamental substance of the interviewees' accounts. Acupuncturists perceived few differences in acupuncture delivery across the two sectors and yet we identified some potentially important differences from their more detailed descriptions. This suggests that future work comparing health care delivery across different sectors would benefit from an ethnographic approach using observations as well as interviews.

The differences that we identified between NHS and private practice delivery of acupuncture have implications for the provision of NHS acupuncture and for our application of research findings generated in the private sector. The NHS provision of CAM is not straightforward. Ernst (2010) found inconsistencies in the rigour with which CAMs are evaluated across NICE guidelines and argued that these therapies should be assessed in the same way as conventional therapies so as to prevent double standards. Franck et al. (2007) argued that "failure [by NICE] to evaluate complementary therapies leads to health inequalities because of uneven access and missed opportunities" (p.506). This national inconsistency may be compounded by local NHS management decisions. Our analysis of practitioners' perspectives adds that even after positive evaluation by NICE, differences and missed opportunities can continue probably because of the constraints placed on CAM delivery in the NHS and the ways in which this differs between Trusts. The major UK acupuncture study that provided some of the impetus for increasing provision on the NHS was delivered in private sector clinics (Thomas, MacPherson, Thorpe, Brazier, Fitter, Campbell, Roman, Walters, \& Nicholl 2006). Our analysis suggests that the acupuncture that is currently being delivered in the NHS may differ from that typically delivered in the private sector. Allowing practitioners to develop individualised treatment plans with patients (in relation to treatment frequency and duration) could bring NHS practice closer to what is seen and has been researched in the private sector. Encouraging and enabling more acupuncturists who are trained in 
Chinese approaches to work in the NHS could also decrease the differences between NHS and private practice acupuncture. Future studies should explore the impact on patients' clinical outcomes of the different ways and environments in which acupuncture is delivered. 


\section{Table 1. Topic Guide for Semi-structured Interviews}

Opening I'm really interested in finding out about the provision and use of

Question acupuncture for pain relief. Please could you tell me about your experience of using it for pain relief?

Main Could you tell me about people who have come to you for

Supplementary acupuncture for pain relief?

Questions Could you take me through a typical consultation?

Could you tell me about the place where you provide your acupuncture?

What factors do you think contribute towards a really good (and bad) acupuncture treatment?

How do you feel about offering acupuncture for pain relief (in the private sector/within the NHS)?

Closing Question Is there anything else that you would like to tell me about your experiences or understanding of acupuncture? 
Table 2. Participants' Characteristics by Healthcare Sector

\begin{tabular}{|c|c|c|c|}
\hline Characteristic & $\begin{array}{l}\text { Private sector only } \\
(\mathrm{n}=7)\end{array}$ & $\begin{array}{l}\text { NHS only } \\
(n=3)\end{array}$ & $\begin{array}{l}\text { Both sectors } \\
(n=6)\end{array}$ \\
\hline \multicolumn{4}{|l|}{ Gender } \\
\hline Female (n, \%) & $6(86 \%)$ & $3(100 \%)$ & $5(83 \%)$ \\
\hline \multicolumn{4}{|l|}{ Dual qualifications/practices } \\
\hline GP & $\checkmark$ & $x$ & $\checkmark$ \\
\hline Physiotherapist & $x$ & $\checkmark$ & $\checkmark$ \\
\hline Nurse & $x$ & $x$ & $\checkmark$ \\
\hline Other CAM & $\checkmark$ & $\checkmark$ & $\checkmark$ \\
\hline \multicolumn{4}{|l|}{ Acupuncture Style } \\
\hline Chinese (incl. 5 Elements) & $\checkmark$ & $x$ & $\checkmark$ \\
\hline Western medical & $x$ & $\checkmark$ & $\checkmark$ \\
\hline Combination of Chinese and & $x$ & $x$ & $\checkmark$ \\
\hline \multicolumn{4}{|l|}{ Western medical } \\
\hline \multicolumn{4}{|l|}{ Clinical Experience } \\
\hline Median number of years practicing & $16(2-22)$ & $6(3-12)$ & $10(3-27)$ \\
\hline
\end{tabular}

Note. $\times$ Indicates no participants working in that sector had that characteristic.

Indicates at least one participant working in that sector had that characteristic. 
Table 3. The Relationship between Codes, Sub-Categories, Categories, and Themes

\begin{tabular}{lll}
\hline Analytic Construct & Definition & Example \\
\hline Code & The most basic unit of coding, generated & Need to listen to \\
& primarily from a close reading of the first & patients \\
& three transcripts. & \\
Subcategory & A sub-classification within categories to & Talking and listening to \\
& allow a more detailed level of analysis. & \\
Aategory & A higher level of coding formed by grouping & Building rapport \\
& similar codes. & \\
Aneme & An underlying or manifest topic that & Acupuncturist-patient \\
& summarised an important (to participants) & relationships are \\
& aspect of acupuncture provision and & important \\
\end{tabular}


Table 4. Summary of Practitioners' accounts of Western Medical and Chinese Approaches to Acupuncture

\begin{tabular}{lll}
\hline & Western Medical Acupuncture & Chinese/5-Element Acupuncture \\
Diagnosis & Symptom-focused & Whole person, tongue/pulse \\
Target Outcomes & Goal-oriented, functional & Holistic \\
History/examination & Problem-focused & Exploration of habits and lifestyle \\
Illustrative Quote & "Talk me through a typical day & "A body's like one big jigsaw, \\
& in your life. How much are you & everything is linked in. Treat the \\
& able to do at home, what kind & body as a whole, I don't like to \\
& of things is it stopping you & compartmentalise it." (Christine, B) \\
& doing, what would you like to & \\
& do that you now can't?" (Steph, \\
& N)
\end{tabular}




\section{Figure 1: Thematic Similarities and Differences between the NHS and Private Practice}

\begin{tabular}{|c|c|c|c|c|c|c|c|c|}
\hline $\begin{array}{l}\text { Themes that } \\
\text { were similar } \\
\text { across sectors }\end{array}$ & \multicolumn{2}{|c|}{$\begin{array}{l}\text { Acupuncture is perceived as } \\
\text { often (but not always) } \\
\text { effective }\end{array}$} & \multicolumn{2}{|c|}{$\begin{array}{c}\text { Perception that acupuncture } \\
\text { would be fundamentally } \\
\text { unchanged by organisational } \\
\text { setting }\end{array}$} & \multicolumn{2}{|c|}{$\begin{array}{l}\text { Acupuncture is often a last } \\
\text { resort for patients }\end{array}$} & \multicolumn{2}{|c|}{$\begin{array}{l}\text { Acupuncturist-patient } \\
\text { relationships are important }\end{array}$} \\
\hline \multirow[t]{2}{*}{$\begin{array}{l}\text { Themes that } \\
\text { Differed } \\
\text { Across } \\
\text { Sectors }\end{array}$} & Availability & Acupuncture & \multicolumn{2}{|c|}{$\begin{array}{l}\text { Opportunities for } \\
\text { Autonomous Practice }\end{array}$} & \multicolumn{2}{|c|}{$\begin{array}{l}\text { Qualifications, training, and } \\
\text { lack of industry regulation }\end{array}$} & \multicolumn{2}{|c|}{$\begin{array}{l}\text { Explanatory theories of } \\
\text { acupuncture, health, and } \\
\text { illness influence practice }\end{array}$} \\
\hline & $\begin{array}{l}\text { NHS: } \\
\text { Restricted by } \\
\text { the provider }\end{array}$ & $\begin{array}{l}\text { Private: } \\
\text { Restrictions } \\
\text { are imposed } \\
\text { by the patient }\end{array}$ & $\begin{array}{l}\text { NHS: } \\
\text { Constrained } \\
\text { by guidelines }\end{array}$ & $\begin{array}{l}\text { Private: } \\
\text { Autonomous } \\
\text { practice }\end{array}$ & $\begin{array}{l}\text { NHS: } \\
\text { Concern } \\
\text { about some } \\
\text { dubious } \\
\text { highly visible } \\
\text { private } \\
\text { clinics }\end{array}$ & $\begin{array}{l}\text { Private: } \\
\text { Concern over } \\
\text { the } \\
\text { comparatively } \\
\text { short training } \\
\text { undertaken by } \\
\text { NHS } \\
\text { biomedical } \\
\text { practitioners }\end{array}$ & $\begin{array}{l}\text { NHS: } \\
\text { Dominant } \\
\text { approach is } \\
\text { Western } \\
\text { acupuncture }\end{array}$ & $\begin{array}{l}\text { Private: } \\
\text { Dominant } \\
\text { approach is } \\
\text { Chinese } \\
\text { acupuncture }\end{array}$ \\
\hline
\end{tabular}




\section{References}

Bennetts, G. 2007: Constitutional five-element acupuncture. Journal of the Australian Traditional-Medicine Society, 13, (3) 159-162.

Bishop, F. L., Zaman, S., \& Lewith, G. T. 2011. Acupuncture for low back pain: a survey of clinical practice in the UK. Complementary Therapies in Medicine . In Press.

Braun, V. and Clarke, V. 2006: Using thematic analysis in psychology. Qualitative Research in Psychology, 3, (2) 77-101.

Breivik, H., Collett, B., Ventafridda, V., Cohen, R., and Gallacher, D. 2006: Survey of chronic pain in Europe: Prevalence, impact on daily life, and treatment. European Journal of Pain, 10, (4) 287-333.

Dale, J. 1997: Acupuncture practice in the UK. Part 1: Report of a survey. Complementary Therapies in Medicine, 5, 215-220.

Dew, K. 2000: Deviant insiders: medical acupuncturists in New Zealand. Social Science \& Medicine, 50, 1785-1795.

Di Blasi, Z., Harkness, E., Ernst, E., Georgiou, A., and Kleijnen, J. 2001: Influence of context effects on health outcomes: a systematic review. The Lancet, 357, 757-762.

Ernst, E. 2010: Assessments of complementary and alternative medicine: the clinical guidelines from NICE. International Journal of Clinical Practice, 64, (10) 1350-1358. 
Evans, M.A., Shaw, A.R.G., Sharp, D.J., Thompson, E.A., Falk, S., Turton, P., and Thompson, T. 2007: Men with cancer: is their use of complementary and alternative medicine a response to needs unmet by conventional care? European Journal of Cancer Care, 16, 517-525.

Ezzo, J., Berman, B., Hadhazy, V.A., Jadad, A.R., Lao, L., and Singh, B.B. 2000: Is acupuncture effective for the treatment of chronic pain? A systematic review. Pain, 86, (3) 217-225.

Franck, L., Chantler, C., and Dixon, M. 2007: Should NICE evaluate complementary and alternative medicine? British Medical Journal, 334, 506.

Furlan, A.D., van Tulder, M., Cherkin, D., Tsukayama, H., Lao, L., Koes, B., and Berman, B. 2005: Acupuncture and dry-needling for low back pain: an updated systematic review within the framework of the Cochrane Collaboration. Spine, 30, (8) 944-963.

Green, S., Buchbinder, R., and Hetrick, S. 2005: Acupuncture for shoulder pain. Cochrane Database Syst Rev (2) CD005319.

Hughes, J.G., Goldbart, J., Fairhurst, E., and Knowles, K. 2007: Exploring acupuncturists' perceptions of treating patients with rheumatoid arthritis. Complementary Therapies in Medicine, 15, (2) 101-108.

Linde, K., Allais, G., Brinkhaus, B., Manheimer, E., Vickers, A., and White, A.R. 2009a: Acupuncture for migraine prophylaxis. Cochrane Database of Systematic Reviews, Issue 1, Art. No.: CD001218. DOI: 10.1002/14651858.CD001218.pub2. 
Linde, K., Allais, G., Brinkhaus, B., Manheimer, E., Vickers, A., and White, A.R. 2009b: Acupuncture for tension-type headache. Cochrane Database of Systematic Reviews, Issue 1, Art. No.: CD007587. DOI: 10.1002/14651858.CD007587.

MacPherson, H., Thorpe, L., and Thomas, K. 2006a: Beyond needling - therapeutic processes in acupuncture care: a qualitative study nested within a low-back pain trial. The Journal of Alternative \& Complementary Medicine, 12, (9) 873-880.

MacPherson, H., Sinclair-Lian, N., and Thomas, K. 2006b: Patients seeking care from acupuncture practitioners in the UK: A national survey. Complementary Therapies in Medicine, 14, (1) 20-30.

MacPherson, H. and Thomas, K. 2008: Self-help advice as a process integral to traditional acupuncture care: Implications for trial design. Complementary Therapies in Medicine, 16, (2) 101-106.

Manheimer, E., White, A., Berman, B., Forys, K., and Ernst, E. 2005: Meta-analysis: acupuncture for low back pain. Annals of Internal Medicine, 142, 651-663.

Paterson, C. and Britten, N. 2008: The patient's experience of holistic care: insights from acupuncture research. Chronic Illness, 4, 264-277.

Price, S., Mercer, S.W., and MacPherson, H. 2006: Practitioner empathy, patient enablement and health outcomes: A prospective study of acupuncture patients. Patient Education and Counseling, 63, (1-2) 239-245. 
Ratcliffe, J., Thomas, K.J., MacPherson, H., and Brazier, J. 2006: A randomised controlled trial of acupuncture care for persistent low back pain: cost effectiveness analysis. British Medical Journal, doi:10.1136/bmj.38932.806134.7C, bmj.

Saks, M. 1992, "The paradox of incorporation: Acupuncture and the medical profession in modern Britain," In Alternative medicine in Britain, M. Saks, ed., Oxford: Clarendon Press, pp. 183-198.

Savigny, P., Kuntze, S., Watson, P., Underwood, M., Ritchie, G., Cotterell, M., Hill, D., Browne, N., Buchanan, E., Coffey, P., Dixon, P., Drummond, C., Flanagan, M., Greenough, C., Griffiths, M., Halliday-Bell, J., Hettinga, D., Vogel, S., \& Walsh, D. 2009: Low back pain. Early management of persistent non-specific low back pain., National Collaborating Centre for Primary Care and Royal College of General Practitioners, London, NICE clinical guideline 88 .

Secretary of State for Health 2010: Government response to the Science and Technology Committee report 'Evidence Check 2: Homeopathy', The Stationery Office Limited, UK.

Shaw, A., Thompson, E.A., and Sharp, D. 2006: Expectations of patients and parents of children with asthma regarding access to complementary therapy information and services via the NHS: a qualitative study. Health Expectations, 9, 343-358.

Thomas, K.J., Coleman, P., and Nicholl, J. 2003: Trends in access to complementary or alternative medicines via primary care in England: 1995-2001 results from a follow up national survey. Family Practice, 20, 575-577. 


\section{Thomas, K.J., MacPherson, H., Thorpe, L., Brazier, J., Fitter, M., Campbell, M.J.,}

Roman, M., Walters, S.J., and Nicholl, J. 2006: Randomised controlled trial of a short course of traditional acupuncture compared with usual care for persistent non-specific low back pain. British Medical Journal, 333, (7569) 623.

Thomas, K.J., Nicholl, J.P., and Fall, M. 2001: Access to complementary medicine via general practice. British Journal of General Practice, 51, 25-30.

Trinh, K., Graham, N., Gross, A., Goldsmith, C.H., Wang, E., Cameron, I.D., and Kay, T.M. 2006: Acupuncture for neck disorders. Cochrane Database of Systematic Reviews, Issue 3, Art. No.: CD004870. DOI: 10.1002/14651858.CD004870.pub3.

White, A., Hayhoe, S., Hart, A., and Ernst, E. 2001: Adverse events following acupuncture: prospective survey of 32,000 consultations with doctors and physiotherapists. British Medical Journal, 323, 485-486.

White, A. and the editorial board of Acupuncture in Medicine 2009: Western medical acupuncture: a definition. Acupuncture in Medicine, 27, (1) 33-35.

Willich, S.N., Reinhold, T., Selim, D., Jena, S., Brinkhaus, B., and Witt, C.M. 2006:

Cost-effectiveness of acupuncture treatment in patients with chronic neck pain. Pain, 125, (12) $107-113$.

Witt, C.M., Lndtke, R., Wegscheider, K., and Willich, S.N. 2010: Physician Characteristics and Variation in Treatment Outcomes: Are Better Qualified and Experienced 
Physicians More Successful in Treating Patients With Chronic Pain With Acupuncture? The Journal of Pain, 11, (5) 431-435.

Wonderling, D., Vickers, A.J., Grieve, R., and McCarney, R. 2004: Cost effectiveness analysis of a randomised trial of acupuncture for chronic headache in primary care. British Medical Journal, 328, (7442) 747.

Yuan, J., Purepong, N., Hunter, R.F., Kerr, D.P., Park, J., Bradbury, I., and McDonough, S. 2009: Different frequencies of acupuncture treatment for chronic low back pain: An assessor-blinded pilot randomised controlled trial. Complementary Therapies in Medicine, 17, (3) 131-140. 


\section{$\underline{\text { Acknowledgements }}$}

We would like to thank all of our participants for volunteering to share their experiences with us. The interviews conducted for this project were undertaken by NA as part of her University of Southampton medical degree and as such expenses (such as travel, transcription) were funded by the Department of Primary Medical Care, University of Southampton School of Medicine. FLB is funded as an Arthritis Research UK Career Development Fellow (grant 18099). GTL's post is supported by a grant from the Rufford Maurice Laing Foundation. 